\title{
Delineation of management zones using mobile measurements of soil apparent electrical conductivity and multivariate geostatistical techniques
}

\author{
F.J. Moral ${ }^{\mathrm{a}, *}$, J.M. Terrón ${ }^{\mathrm{b}}$, J.R. Marques da Silva ${ }^{\mathrm{c}}$ \\ a Departamento de Expresión Gráfica, Escuela de Ingenierías Industriales, Universidad de Extremadura. Avda. de Elvas, s/n. 06071 Badajoz, Spain \\ ${ }^{\mathrm{b}}$ Departamento de Cultivos Extensivos, Centro de Investigación La Orden-Valdesequera, Consejería de Economía, Comercio e Innovación, Junta de Extremadura, 06187 Guadajira, \\ Badajoz, Spain \\ ${ }^{\mathrm{c}}$ ICAAM, Rural Engineering Department, Évora University, P.O. BOX 94, 7002-554 Évora, Portugal
}

\section{A R T I C L E I N F O}

\section{Article history:}

Received 25 September 2009

Received in revised form 27 November 2009

Accepted 9 December 2009

\section{Keywords:}

Regression kriging

Site-specific crop management

Soil electrical conductivity

Principal component analysis

Fuzzy c-means

\begin{abstract}
A B S T R A C T
Site-specific management promotes the identification and management of areas within the field, which represent subfield regions with homogeneous characteristics (management zones). However, determination of subfield areas is difficult because of the complex combination of factors which could affect crop yield. One possibility to capture yield variability is the use of soil physical properties to define the management zones as they are related to plant available water.

With the aim of characterizing the spatial variability of the main soil physical variables and using this information to determine potential management zones, soil samples were taken from 70 locations in a 33-ha field in Badajoz, southwestern Spain. Firstly, accurate spatial distribution maps of the soil attributes were generated by using regression kriging as the most suitable algorithm in which exhaustive secondary information on soil apparent electrical conductivity (ECa) was incorporated. ECa measurements were carried out with a Veris 3100 operating in both shallow $(0-30 \mathrm{~cm})$, ECs, and deep $(0-90 \mathrm{~cm})$, ECd, mode. Clay, coarse sand and fine sand were the soil physical properties which exhibited higher correlation with ECa (positively correlated with the finer texture component, clay, and negatively correlated with the coarser ones, coarse and fine sands), particularly with ECs. Thus, this was the secondary variable used to obtain the kriged maps. Later, principal component analysis and fuzzy cluster classification were performed to delineate management zones, resulting in two subfields to be managed separately. This number of subfields was determined using the fuzzy performance index and normalized classification entropy as the way to optimize the classification algorithm.
\end{abstract}

(c) 2009 Elsevier B.V. All rights reserved.

\section{Introduction}

High spatial variability is usually found in soils due to many physical, biological and chemical processess acting simultaneously with different intensities. In consequence, uniform management of fields does not take into account the spatial variability, and it is not the most effective management strategy. Precision agriculture is considered the most viable approach for achieving sustainable agriculture (Corwin et al., 1999). Particularly, site-specific crop management (SSCM) is a form of precision agriculture whereby decisions on resource application and agronomic practices are improved to better match soil and crop requirements as they vary in the field. SSCM advocates the identification of regions (management zones) within the area delimited by field boundaries. These subfield regions constitute areas of the field with

\footnotetext{
* Corresponding author. Tel.: +34 924 289600; fax: +34 924289601.

E-mail address: fjmoral@unex.es (F.J. Moral).
}

similar characteristics, such as texture, topography and nutrient levels. However, it is difficult to accurately define the management zones due to the complex interactions of all factors that could affect crop yield. Furthermore, the fact that factors interact in a dynamic way can make very difficult to determine the management by subfields. According to Fraisse et al. (2001), crop production potential is strongly related to plant available water so its variability can be approximately determined on the basis of soil physical properties and topographic characteristics, when topography change significantly in the field.

SSCM uses rapidly developing information and electronic technologies to change the management of soils and crops considering the field variations spatially and temporarily. To characterize within-field variability of edaphic properties, with the aim to be applied to SSCM, measurements of apparent soil electrical conductivity (ECa) is one of the most reliable technique (e.g., Corwin and Lesch, 2003). Especially, the application of geospatial measurements of ECa has a great potential to provide spatial information for optimizing soil sampling to better 